\title{
The non-invasive evaluation of heart function in patients with an acute myocardial infarction: The role of impedance cardiography
}

\author{
Lukasz Lewicki ${ }^{1}$, Marta Fijalkowska ${ }^{2}$, Maciej Karwowski ${ }^{2}$, Konrad Siebert ${ }^{1}$, \\ Grzegorz Redlarski ${ }^{3}$, Aleksander Palkowski ${ }^{3}$, Radoslaw Targonski ${ }^{2}$, Janusz Siebert ${ }^{1,4}$ \\ 1University Center for Cardiology, Gdansk, Poland \\ ${ }^{2}$ Pomeranian Cardiology Centers, Wejherowo, Poland \\ ${ }^{3}$ Department of Mechatronics and High Voltage Engineering, \\ Gdansk University of Technology, Gdansk, Poland \\ ${ }^{4}$ Department of Family Medicine, Medical University of Gdansk, Poland
}

\begin{abstract}
Background: The purpose of this study was to analyze hemodynamic changes in patients treated with percutaneous coronary intervention (PCI) at an early stage of acute myocardial infarction (AMI) and at 1-month follow-up.

Methods: Patients with AMI $(n=27)$ who underwent PCI were analyzed using impedance cardiography (ICG). ICG data were collected continuously (beat by beat) during the whole PCI procedure and thereafter at every $60 \mathrm{~s}$ for the next $24 \mathrm{~h}$. Blood pressure was taken every $10 \mathrm{~min}$ and stored for analysis. Additionally the following parameters were measured: cardiac index (CI), stroke volume index (SVi), left cardiac work index (LCWi), contractility index (CTi), ventricular ejection time (VET), systemic vascular resistance index (SVRi), thoracic fluid content index (TFCi) and heart rate (HR).

Results: In the first $24 \mathrm{~h}$ after PCI all the contractility parameters including CI, SVi, LCWi, CTi and VET significantly decreased, whereas HR, SVRi and TFCi increased compared to baseline. All of the parameters examined got normalized at 1 month. The CI, SVi, LCWi, CTi, SVRi did not significantly differ from baseline, however the HR and VET were significantly lower compared to first day after PCI Conclusions: Cardiac performance deteriorates early after PCI and normalizes after 1 month in patients with an AMI. ICG is useful for hemodynamic monitoring of AMI patients during and after invasive therapy. (Cardiol J 2021; 28, 1: 77-85)
\end{abstract}

Key words: impedance cardiography, acute myocardial infarction, hemodynamics, percutaneous coronary intervention

\section{Introduction}

Although a commonly used early reperfusion treatment in AMI, by using either thrombolysis or primary percutaneous coronary intervention (PCI) significantly limits myocardial damage, the process of reperfusion itself may induce so called ischemic reperfusion injury (IRI) [1-4]. The pathogenesis of this phenomenon is complex and may be related to myocardial stunning [5], microvascular obstruction [6-8], lethal myocardial reperfusion injury [3] or reperfusion-induced ventricular arrhythmias [9].

Despite significant progress in PCI technology and antiplatelet therapy, the IRI remains an important therapeutic target in patients with AMI. Therefore, it is fundamental to stratify the risk at an early stage of AMI and to evaluate heart function in a real-time manner.

Address for correspondence: Łukasz Lewicki, MD, PhD, University Center for Cardiology, ul. Dębinki 2, 80-211 Gdańsk, Poland, e-mail: luklewicki@gmail.com

Received: 01.10.2019 Accepted: 21.10.2019

This article is available in open access under Creative Common Attribution-Non-Commercial-No Derivatives 4.0 International (CC BY-NC-ND 4.0) license, allowing to download articles and share them with others as long as they credit the authors and the publisher, but without permission to change them in any way or use them commercially. 
Recently used monitoring of patient's hemodynamic profile is based mainly on electrocardiographic (ECG) analysis, blood pressure (BP) monitoring and bedside transthoracic echocardiography (TTE). The three-dimensional ultrasonography and magnetic resonance imaging are accurate in the evaluation of myocardial function, but they involve high costs, and require qualified personnel. An invasive heart catheterization with Swan-Ganz does not occur in the guidelines because of its complexity and complication risk. Therefore, in patients requiring intensive care after AMI, non-invasive hemodynamic monitors such as impedance cardiography (ICG) might be an interesting option in the treatment strategy.

The ICG is a non-invasive diagnostic method based on the detection of thoracic electrical bioimpedance across the thorax during systole and diastole of the heart. The ICG allows monitoring of hemodynamic parameters, comprising for instance: stroke volume (SV), cardiac output (CO), systemic vascular resistance (SVR), thoracic fluid content (TFC) and many others.

Transthoracic bio-impedance is a technique, which quantifies mechanical activity of the heart instead of its electrical activity. A fundamental principle of transthoracic bio-impedance is that it uses direct measurement of baseline impedance, ventricular ejection time, heart rate, and early diastolic filling ratio. These parameters are measured and used to compute other hemodynamic parameters.

Application of ICG for the determination of hemodynamic parameters is based on the following principle: different tissues, i.e. muscles, bones, fat and blood have specific electrical properties. Among them, the blood is the most conductive body tissue in the thorax. The differences in thoracic electrical impedance are essentially created by changes in the velocity and blood volume in the aorta.

The clinical use of ICG has been described recently.

In patients after off-pump coronary artery bypass grafting, the findings obtained from ICG were correlated with B-type natriuretic peptide (BNP) levels and TTE measurements for the evaluation of cardiac hemodynamic changes during perioperative period [10].

Louvaris et al. [11] compared concurrent CO measurements captured by ICG (COIC) and by the indocyanine green dye dilution method $\left(\mathrm{CO}_{\mathrm{DD}}\right)$ in patients with chronic obstructive pulmonary disease. They found a strong correlation between $\mathrm{CO}_{\mathrm{IC}}$ and $\mathrm{CO}_{\mathrm{DD}}$. Malek et al. [12] analyzed hemodynamic data obtained from ICG, TTE and gas exchange analysis during rest and exercise among wheelchair rugby players. Their analysis showed a good correlation between the methods, however, interestingly, a CO was overestimated by ICG.

Last but not least, an impaired hemodynamic response to exercise in hypertensive females with dyspnea was proved by ICG [13].

Thus, the aim of the present study was to evaluate the dynamic changes in the hemodynamic profile of patients during an early stage of AMI and at 1-month follow-up.

\section{Methods}

Herein, 27 AMI patients were included. The ECG of 20 patients revealed on admission persistent ST-segment elevation myocardial infarction (STEMI) and the other 7 were diagnosed with non-ST-segment elevation myocardial infarction (NSTEMI). All patients underwent urgent coronary catheterization with subsequent PCI.

The ICG was performed with PhysioFlow Q-Link (Manatec Biomedical, Paris, France) and TTE examination was obtained by using Aloka Prosound Alpha 6.

\section{Bioimpednace measurements}

The PhysioFlow ${ }^{\circledast}$ Q-LinkTM is a noninvasive hemodynamic evaluation system to assess patient cardiovascular state using analyses of transthoracic bio-impedance signals.

PhysioFlow System measures the change in impedance by injecting a high frequency alternating electrical current $(66 \mathrm{kHz})$ of low magnitude (4.5 mA peak to peak) towards the thorax between two electrodes positioned on the neck and another two positioned on the xiphoid process. The use of a high frequency current eliminates the risk of interference with heart and brain bioelectrical activity.

For measurement at rest the electrodes were placed on the thorax as presented in Figure 1.

Impedance cardiography was initiated in the cathlab just before a coronary catheterization. Four ICG and two ECG pre-gelled electrodes were placed accordingly: two $(Z 1, Z 2)$ on the left side of patient's neck, one (Z3) at the level of the xiphoid and the last one (Z4) just to the right of $Z 3$. The ICG data were collected continuously (beat by beat) during the whole PCI procedure and later, after PCI, the recorded signal was averaged for each $10 \mathrm{~s}$ during the next $24 \mathrm{~h}$ automatically. BP was taken each 10 min during PCI and stored for analysis. The following parameters were measured beat-to-beat continuously: cardiac index (CI [1/ $\left.\left./ \mathrm{min} / \mathrm{m}^{2}\right]\right)$, stroke volume index $\left(\mathrm{SVi}\left[\mathrm{mL} / \mathrm{m}^{2}\right]\right)$, left 


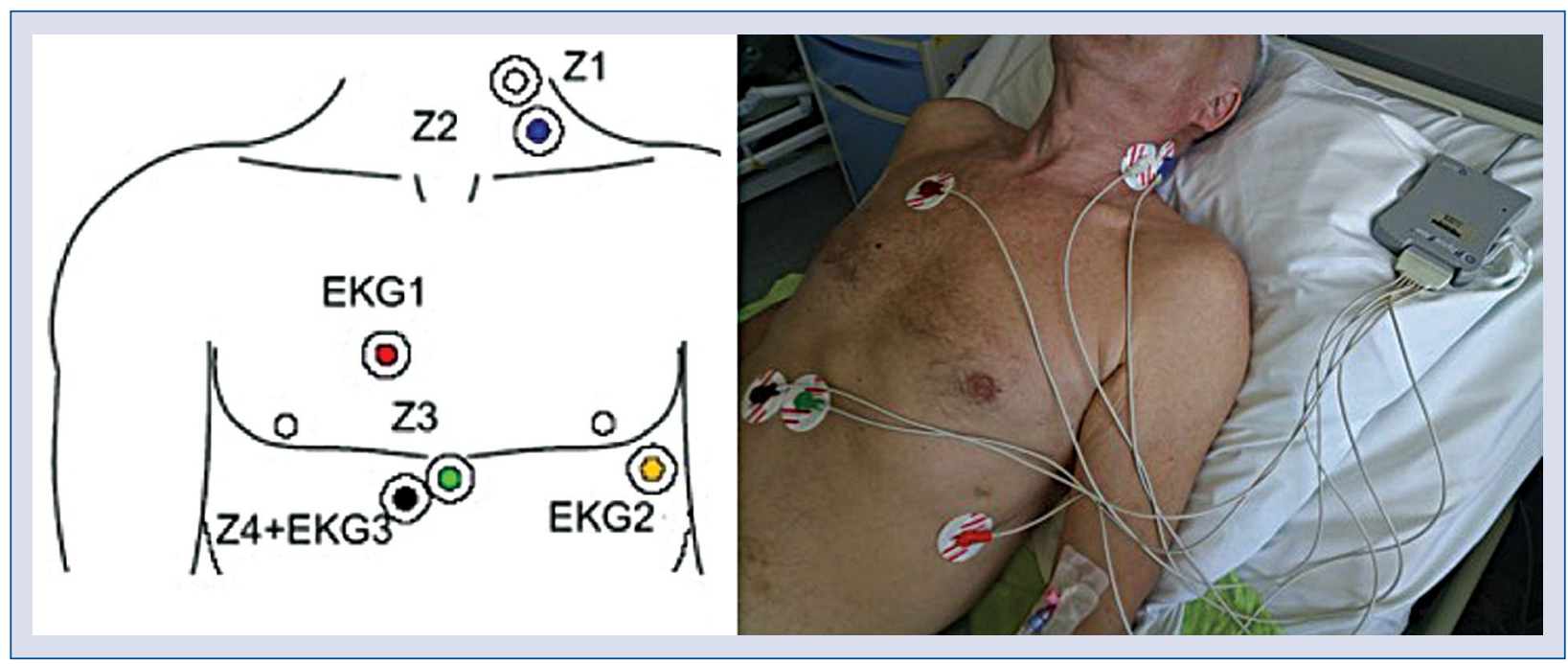

Figure 1. The position current $(Z 1, Z 4)$ and voltage $(Z 2, Z 3)$ electrodes on the thorax - scheme and original photo. The electrodes were positioned on the neck, the back at the level of the xiphoid on the left-hand side of the spine, the left-hand side lower ribs and the right clavicle.

Table 1. The clinical and angiographic data of 27 patients with an acute myocardial infarction (MI).

\begin{tabular}{lc}
\hline Age [years] & $62.3 \pm 13.4$ \\
Male/female & $17 / 10$ \\
BMI $\left[\mathrm{kg} / \mathrm{m}^{2}\right]$ & $27.7 \pm 4.8$ \\
STEMI/NSTEMI & $20 / 7$ \\
Arterial hypertension & 14 \\
Diabetes & 9 \\
History of previous MI & 2 \\
REF-HF & 9 \\
History of stroke & 4 \\
COPD & 4 \\
History of previous PCI & 4 \\
LVEF at 1st day & $39.4 \pm 9.2$ \\
LVEF at follow up & $52.5 \pm 5.4$ \\
Infarct related artery: & \\
LM & 2 \\
LAD & 11 \\
CX & 2 \\
RCA & 12 \\
TIMI 3 after PCl & 25 \\
\hline
\end{tabular}

$\mathrm{BMI}$ - body mass index; STEMI — ST segment elevation myocardial infarction; NSTEMI - non ST segment elevation myocardial infarction; REF-HF — reduced ejection fraction heart failure; COPD - chronic obstructive pulmonary disease; $\mathrm{PCl}$ - percutaneous coronary intervention; LVEF - left ventricular ejection fraction; LM - left main coronary artery; LAD — left artery descending artery; $\mathrm{CX}$ - circumflex artery; RCA - right coronary artery; TIMI thrombolysis in myocardial infarction scale

cardiac work index (LCWi $\left.\left[\mathrm{kg} \cdot \mathrm{m} / \mathrm{m}^{2}\right]\right)$, contractility index (CTi), ventricular ejection time (VET [ms]), systemic vascular resistance index (SVRi [dyn·s/ $\left./ \mathrm{cm}^{5} \cdot \mathrm{m}^{2}\right]$ ), thoracic fluid content index (TFCi $\left.\left[1 / \mathrm{k} \Omega \cdot \mathrm{m}^{2}\right]\right)$ and heart rate (HR $\left.[1 / \mathrm{min}]\right)$. Specific calculations conducted as part of a further analysis were based on the values obtained in the supine position. The quality of all measurements was high, and no relevant errors were noted.

\section{Echocardiographic measurements}

The measurements were taken in $24 \mathrm{~h}$ after AMI and at the follow-up visit. The examinations were taken as recommended by the European Society of Cardiology and American Heart Association. Patients were imaged in the left lateral decubitus position. Images were obtained in parasternal and apical projections. A left ventricular ejection fraction (LVEF) was determined by using the Simpson method for biplane assessment. All examinations were performed by the same investigator.

Every patient has been scheduled for a followup visit after 30 days in order to perform TTE, clinical examination and ICG hemodynamics was continuous for a 20 min measurement.

\section{Statistical analysis}

To test the validity of the data a series of statistical tests were prepared including: the Shapiro-Wilk test and ANOVA statistic. All statistical analysis presented was conducted using Python programming language (v. 3.6.1) and a selection of supporting mathematical packages: NumPy and Pandas for basic mathematical operations, 


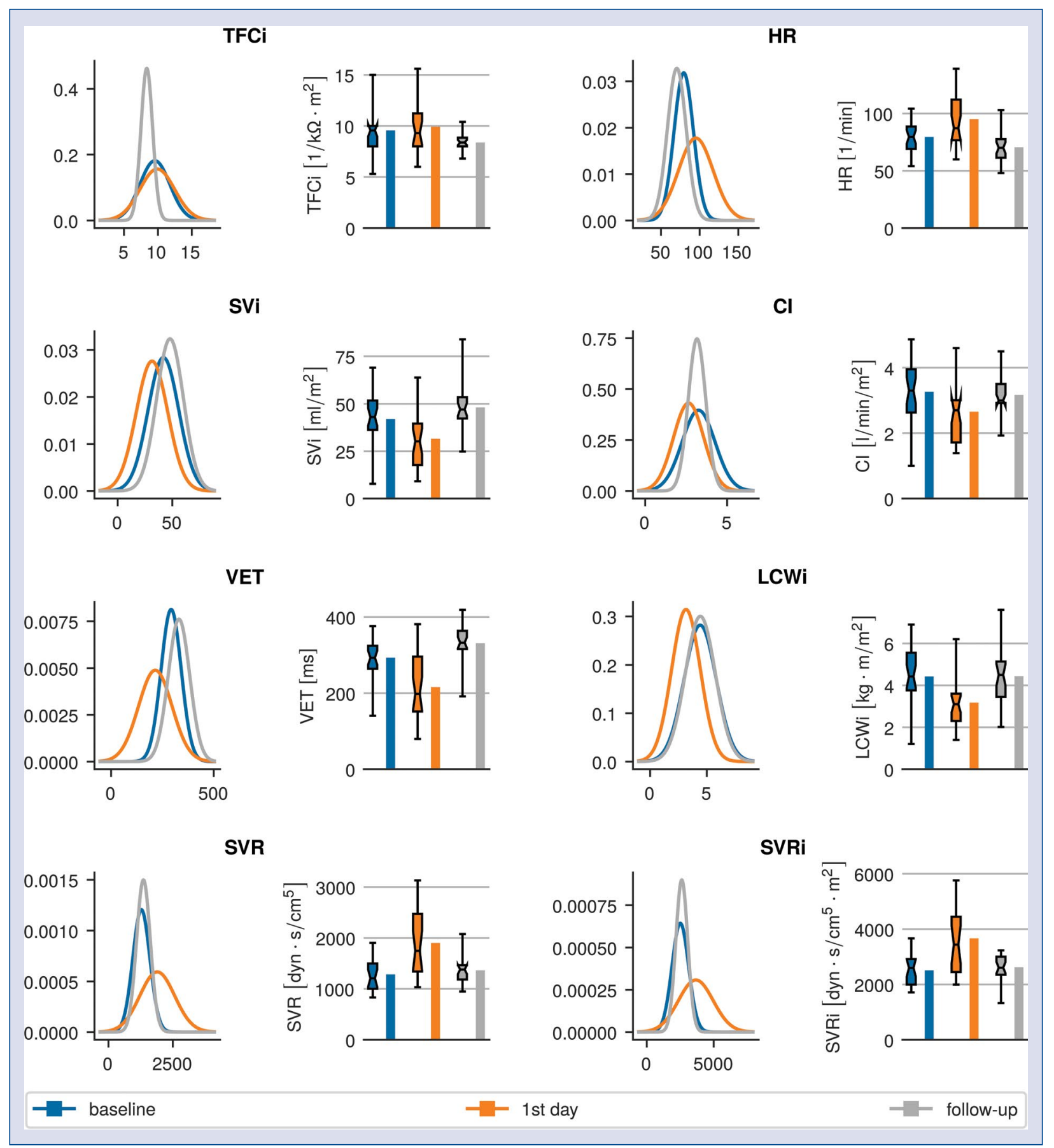

Figure 2. Comparison of hemodynamic parameters in 27 patients with myocardial infarction recorded before percutaneous coronary intervention (PCl) and at 1 and 30 days after $\mathrm{PCl}$; abbreviations - see text.

and SciPy for all relevant statistical computations. Plots were generated using Python programming language (v. 3.6.1) and the Matplotlib package.

\section{Results}

In the group observed there were more males than females (Table 1). The majority of patients were hospitalized with STEMI and the most com- mon culprit lesions were right coronary artery or left anterior descending branch. All patients underwent PCI. A good angiographic result (TIMI 3) was achieved in all but two subjects.

The results are presented in Figure 2 and Table 2. On the first day after PCI, a significant decrease in hemodynamic parameters describing heart contractility was observed: CI, LCWi, CTi and VET. The contractility index reflects an amplitude 
Table 2. Hemodynamic profile during the early stage of acute myocardial infarction and at the 1-month follow-up in 27 patients.

\begin{tabular}{|c|c|c|c|}
\hline Parameter & Measurement day & Mean \pm SD & $\mathbf{P}$ \\
\hline \multirow[t]{3}{*}{ TFCi $\left[1 / \mathrm{k} \Omega \cdot \mathrm{m}^{2}\right]$} & 1/ Just before PCI & $9.6 \pm 2.2$ & 1 vs. $2: p=0.62$ \\
\hline & $2 / 1^{\text {st }}$ day after $\mathrm{PCl}$ & $9.9 \pm 2.6$ & 1 vs. $3: p=0.01$ \\
\hline & $3 / 30$ days after $\mathrm{PCl}$ & $8.4 \pm 0.9$ & 2 vs. $3: p=0.006$ \\
\hline \multirow[t]{3}{*}{$\mathrm{HR}[1 / \mathrm{min}]$} & 1/ Just before PCI & $79.5 \pm 12.5$ & 1 vs. $2: p=0.003$ \\
\hline & 2/ $1^{\text {st }}$ day after $\mathrm{PCl}$ & $95.1 \pm 22.5$ & 1 vs. $3: p=0.01$ \\
\hline & 3/ 30 days after $\mathrm{PCl}$ & $70.5 \pm 12.2$ & 2 vs. $3: p=6.94 E-06$ \\
\hline \multirow[t]{3}{*}{$\mathrm{SVi}\left[\mathrm{mL} / \mathrm{m}^{2}\right]$} & 1/ Just before PCl & $42.0 \pm 14.1$ & 1 vs. $2: p=0.01$ \\
\hline & $2 / 1^{\text {st }}$ day after $\mathrm{PCl}$ & $31.5 \pm 14.5$ & 1 vs. $3: p=0.098$ \\
\hline & 3/ 30 days after $\mathrm{PCl}$ & $48.0 \pm 12.3$ & 2 vs. $3: p=3.75 E-05$ \\
\hline \multirow[t]{3}{*}{$\mathrm{Cl}\left[\mathrm{l} / \mathrm{min} / \mathrm{m}^{2}\right]$} & 1/ Just before PCl & $3.3 \pm 1.0$ & 1 vs. $2: p=0.025$ \\
\hline & $2 / 1^{\text {st }}$ day after $\mathrm{PCl}$ & $2.7 \pm 0.9$ & 1 vs. $3: p=0.669$ \\
\hline & $3 / 30$ days after $\mathrm{PCl}$ & $3.2 \pm 0.5$ & 2 vs. $3: p=0.016$ \\
\hline \multirow[t]{3}{*}{ VET [ms] } & 1/ Just before PCI & $292.9 \pm 49.1$ & 1 vs. $2: p=9.93 E-05$ \\
\hline & 2/ $1^{\text {st }}$ day after $\mathrm{PCl}$ & $215.6 \pm 81.7$ & 1 vs. $3: p=0.008$ \\
\hline & $3 / 30$ days after $\mathrm{PCl}$ & $331.0 \pm 52.4$ & 2 vs. $3: p=1.01 E-07$ \\
\hline \multirow[t]{3}{*}{$\mathrm{LCWi}\left[\mathrm{kg} \cdot \mathrm{m} / \mathrm{m}^{2}\right]$} & 1/ Just before PCl & $4.4 \pm 1.4$ & 1 vs. $2: p=0.001$ \\
\hline & 2/ $1^{\text {st }}$ day after $\mathrm{PCl}$ & $3.2 \pm 1.3$ & 1 vs. $3: p=0.969$ \\
\hline & $3 / 30$ days after $\mathrm{PCl}$ & $4.4 \pm 1.3$ & 2 vs. $3: p=0.0008$ \\
\hline \multirow[t]{3}{*}{ SVRi $\left[\mathrm{dyn} \cdot \mathrm{s} / \mathrm{cm}^{5} \cdot \mathrm{m}^{2}\right]$} & 1/ Just before PCI & $2506.3 \pm 620.4$ & 1 vs. $2: p=0.02$ \\
\hline & 2/ $1^{\text {st }}$ day after $\mathrm{PCl}$ & $3663.7 \pm 1296.5$ & 1 vs. $3: p=0.03$ \\
\hline & $3 / 30$ days after $\mathrm{PCl}$ & $2616.2 \pm 443.8$ & 2 vs. $3: p=0.02$ \\
\hline \multirow[t]{3}{*}{ SVR [dyn·s/cm $\left.{ }^{5}\right]$} & 1/ Just before PCI & $1282.2 \pm 331.0$ & 1 vs. $2: p=0.02$ \\
\hline & 2/ $1^{\text {st }}$ day after $\mathrm{PCl}$ & $1899.0 \pm 673.8$ & 1 vs. $3: p=0.03$ \\
\hline & $3 / 30$ days after $\mathrm{PCl}$ & $1482.8 \pm 534.5$ & 2 vs. $3: p=0.02$ \\
\hline \multirow[t]{3}{*}{$\mathrm{SABP}[\mathrm{mmHg}$} & 1/ Just before PCI & $132.5 \pm 25.7$ & 1 vs. $2: p=0.41$ \\
\hline & 2/ $1^{\text {st }}$ day after $\mathrm{PCl}$ & $127.0 \pm 21.4$ & 1 vs. $3: p=0.19$ \\
\hline & $3 / 30$ days after $\mathrm{PCl}$ & $141.7 \pm 24.0$ & 2 vs. $3: p=0.02$ \\
\hline \multirow[t]{3}{*}{$\mathrm{DABP}[\mathrm{mmHg}]$} & 1/ Just before PCI & $78.0 \pm 14.9$ & 1 vs. $2: p=0.18$ \\
\hline & 2/ $1^{\text {st }}$ day after $\mathrm{PCl}$ & $73.1 \pm 10.7$ & 1 vs. $3: p=0.96$ \\
\hline & $3 / 30$ days after $\mathrm{PCl}$ & $77.8 \pm 10.5$ & 2 vs. $3: p=0.12$ \\
\hline \multirow[t]{3}{*}{ MABP $[\mathrm{mmHg}]$} & 1/ Just before PCI & $101.5 \pm 18.6$ & 1 vs. $2: p=0.24$ \\
\hline & $2 / 1^{\text {st }}$ day after $\mathrm{PCl}$ & $96.1 \pm 14.0$ & 1 vs. $3: p=0.48$ \\
\hline & 3/ 30 days after $\mathrm{PCl}$ & $104.9 \pm 14.6$ & 2 vs. $3: p=0.03$ \\
\hline
\end{tabular}

Hemodynamic parameters measured by impedance cardiography. The $\mathrm{p}$-values are based on the $\mathrm{AVOVA}$ test. $\mathrm{Cl}-\mathrm{cardiac}$ index $\left[\mathrm{l} / \mathrm{min} / \mathrm{m}^{2}\right]$; $\mathrm{CO}$ - cardiac output [l/min]; SVRi — systemic vascular resistance index [dyn·s/cm5·m2]; SVR - systemic vascular resistance [dyn·s/cm5]; $\mathrm{HR}$ - heart rate [1/min]; SVi — stroke volume index [mL/m2]; LCWi — cardiac work index [kg. $\mathrm{m} / \mathrm{m} 2]$; VET — ventricular ejection time [ms]; $\mathrm{TFCi}$ - thoracic fluid content index $[1 / \mathrm{k} \Omega \cdot \mathrm{m} 2], \mathrm{SABP}$ - systolic arterial blood pressure [mmHg], DABP — diastolic arterial blood pressure $[\mathrm{mmHg}] ; \mathrm{MABP}$ - mean arterial blood pressure $[\mathrm{mmHg}]$

of the first derivative $\mathrm{dz} / \mathrm{dt}$ was significantly decreased during first day after PCI $(\mathrm{p}<0.002)$ and had increased at the time of follow-up $(\mathrm{p}<0.004)$.

In contrast, during the same period, an increase in HR and SVRi was noticed during the first day after PCI compared to baseline, but decreased after 1 month (Fig. 1).
At follow-up CI, SVi, LCWi, CTi, SVRi did not differ from baseline. Heart rate decreased and ventricular ejection time was significantly longer compared to the first day after PCI.

The LVEF was significantly higher compared to $24 \mathrm{~h}$ after PCI and at follow-up $(39.4 \% \pm 9$ vs. $52.6 \% \pm 5, \mathrm{p}<0.01)$. 


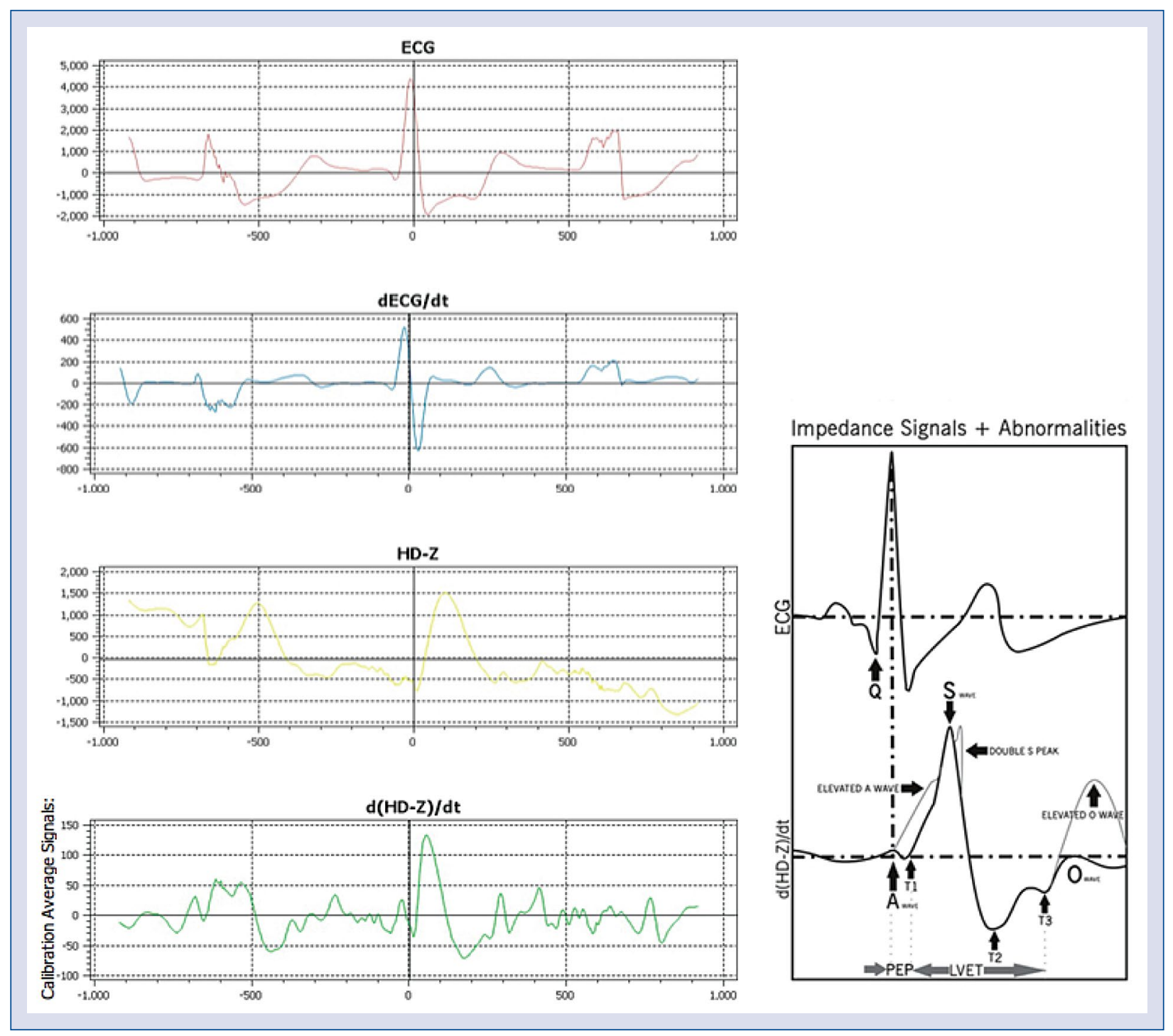

Figure 3. Averaged electrocardiogram and impedance signal in a patient during percutaneous coronary intervention.

The examples of averaged electrocardiogram and impedance signals are presented in Figures 3,4 and 5 .

\section{Discussion}

In this single-center study changes were analyzed in the hemodynamic profile of AMI patients by using ICG. Although a good correlation between impedance diagnostics and invasive assessment of cardiac output and systemic vascular resistance has been reported $[10,11]$, thus far, data is mostly limited to heart failure [12-19] and with only a few AMI subsets examined [20-22].

Herewith, despite an early and successful primary PCI this study presents that, a contractil- ity of a myocardium did not improve immediately and, interestingly, it became worse during the first day. This observation was followed by an increase in systemic vascular resistance and HR, which could be explained as a compensatory reaction for maintaining cardiac output in consideration of decreased cardiac contractility. Chen et al. [23] observed that HR and BP significantly decreased 7 days after primary PCI, whereas other ICG parameters remained unchanged in an AMI setting. In contrast to the present findings, that were focused on the very early stage of AMI, including the first hours after PCI - in a study by Chen et al. [23], the authors might have overlooked the early changes.

The observed transient hemodynamic deterioration may appear as a consequence of "myocar- 


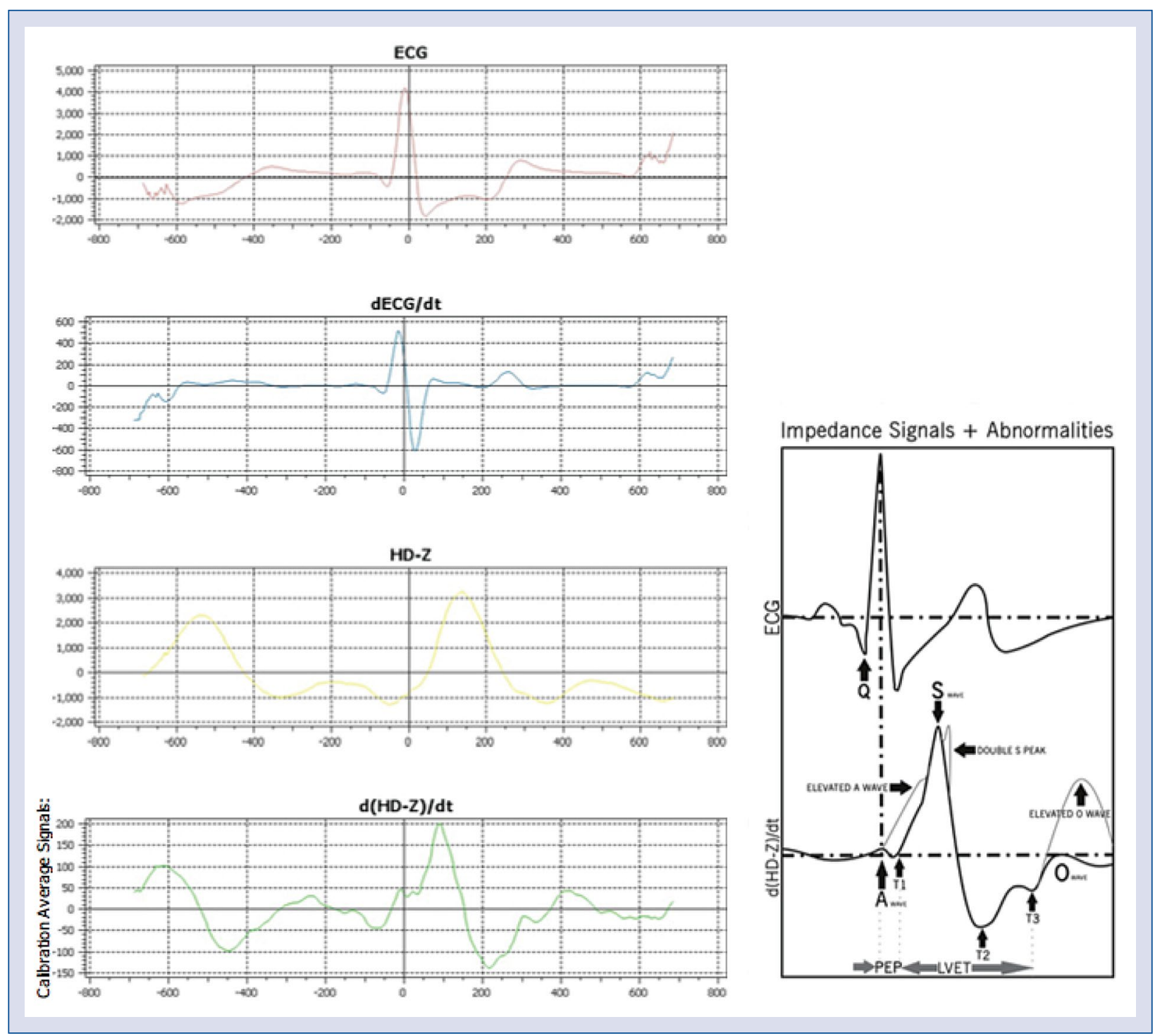

Figure 4. Averaged electrocardiogram and impedance signal in a patient after percutaneous coronary intervention.

dial stunning". This phenomenon is described as a reversible post-ischemic contractile dysfunction, one of the forms of IRI. All parameters that characterized myocardial contractility returned to a normal range after 1 month, which corresponds to the reversible nature of myocardial stunning.

Decreased HR at follow up vs. baseline could be explained either by contractility improvement, or as well as by beta-blockers routinely included in treatment.

The TFCi that reflects thoracic fluid content, significantly decreased at follow-up in comparison to baseline. The transient elevation of this parameter observed on the first day, post PCI, may be related to common in-hospital fluid overload: contrast agent, intravenous saline etc. Malfatto et al. [24] showed good correlation between the TFC and an increased pulmonary capillary wedge pressure. The higher TFCi may also reflect an exacerbation of left ventricle failure. In another analysis, Sadauskas et al. [16] found a moderately strong relationship between $\mathrm{BNP}$ and TFCI.

The pathogenesis of IRI is still not completely understood. Several mechanisms have been proposed: $\mathrm{Ca} 2+$ overload, oxidative stress or inflammatory response [1,23].

As IRI is a serious clinical problem among AMI patients, it requires detailed monitoring of the hemodynamics during hospitalization on intensive coronary care units (ICCU). ICG seems to be an easy and useful method for precise monitoring of patients with AMI on ICCU. Herewith, is reported a detailed pattern of changes in ICG hemodynamic 


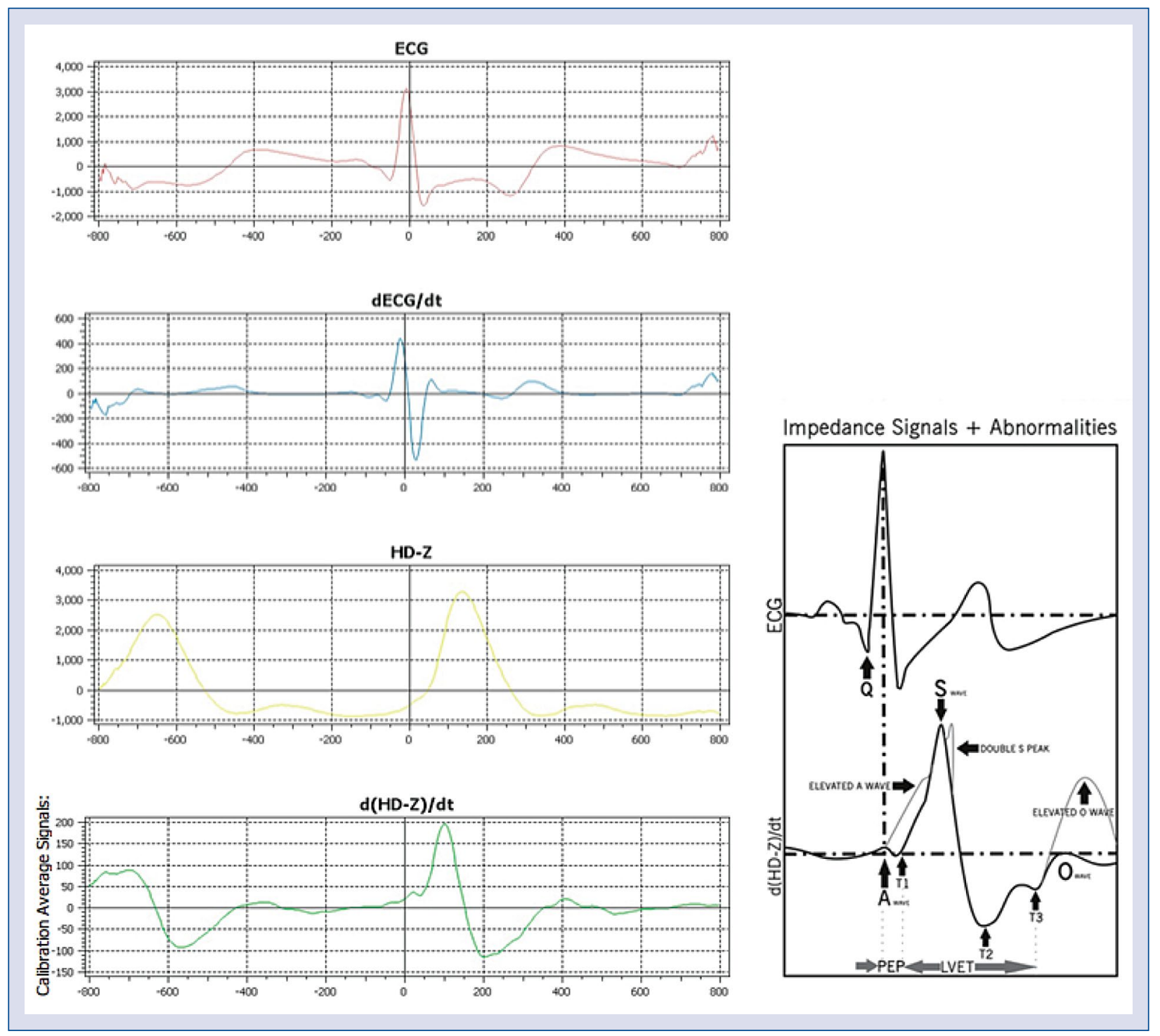

Figure 5. Averaged electrocardiogram and impedance signal in a patient 30 days after percutaneous coronary intervention.

profile of patients early after PCI and at 30 day follow-up. This method is potentially helpful in modifying intensive therapy with fluids or inotropes in clinical routine.

\section{Conclusions}

Despite a successful PCI, cardiac contractility deteriorates early after PCI and normalizes after one month in AMI patients.

Impedance cardiography is useful for noninvasive hemodynamic monitoring in ICCU patients, providing an optimal hemodynamic profile and a better understanding of myocardial stunning processes.

Conflict of interest: None declared

\section{References}

1. Hausenloy DJ, Yellon DM. Myocardial ischemia-reperfusion injury: a neglected therapeutic target. J Clin Invest. 2013; 123(1): 92-100, doi: 10.1172/JCI62874, indexed in Pubmed: 23281415.

2. Braunwald E, Kloner RA. Myocardial reperfusion: a doubleedged sword? J Clin Invest. 1985; 76(5): 1713-1719, doi: 10.1172/ JCI112160, indexed in Pubmed: 4056048.

3. Piper HM, García-Dorado D, Ovize M. A fresh look at reperfusion injury. Cardiovasc Res. 1998; 38(2): 291-300, doi: 10.1016/ s0008-6363(98)00033-9, indexed in Pubmed: 9709390.

4. Yellon D, Hausenloy D. Myocardial reperfusion injury. New Engl J Med. 2007; 357(11): 1121-1135, doi: 10.1056/nejmra071667.

5. Kloner RA, Bolli R, Marban E, et al. Medical and cellular implications of stunning, hibernation, and preconditioning: an NHLBI workshop. Circulation. 1998; 97(18): 1848-1867, doi: 10.1161/01. cir.97.18.1848, indexed in Pubmed: 9603540. 
6. Krug A, Korb G. Blood supply of the myocardium after temporary coronary occlusion. Circ Res. 1966; 19(1): 57-62, doi: 10.1161/01.res.19.1.57, indexed in Pubmed: 5912914.

7. Ito H. No-reflow phenomenon and prognosis in patients with acute myocardial infarction. Nature Clin Pract Cardiovasc Med. 2006; 3(9): 499-506, doi: 10.1038/ncpcardio0632.

8. Luo AK, Wu KC. Imaging microvascular obstruction and its clinical significance following acute myocardial infarction. Heart Fail Rev. 2006; 11(4): 305-312, doi: 10.1007/s10741-006-0231-0, indexed in Pubmed: 17131076.

9. Hearse DJ, Tosaki A. Free radicals and reperfusion-induced arrhythmias: protection by spin trap agent PBN in the rat heart. Circ Res. 1987; 60(3): 375-383, doi: 10.1161/01.res.60.3.375, indexed in Pubmed: 3581446.

10. Niu X, Zhang Q, Xiao D, et al. A retrospective study of hemodynamic changes in patients after off-pump coronary artery bypass graft surgery using impedance cardiography. Med Sci Monit. 2019; 25: 3454-3462, doi: 10.12659/MSM.913289, indexed in Pubmed: 31073116.

11. Louvaris Z, Spetsioti S, Andrianopoulos V, et al. Cardiac output measurement during exercise in COPD: A comparison of dye dilution and impedance cardiography. Clin Respir J. 2019; 13(4): 222-231, doi: 10.1111/crj.13002, indexed in Pubmed: 30724023

12. Małek ŁA, Mróz A, Czajkowska A, et al. Accuracy of impedance cardiography for hemodynamic assessment during rest and exercise in wheelchair rugby players. Res Q Exerc Sport. 2019; 90(3): 336-343, doi: 10.1080/02701367.2019.1600651, indexed in Pubmed: 31082312.

13. Kurpaska M, Krzesiński P, Gielerak G, et al. Exercise impedance cardiography reveals impaired hemodynamic responses to exercise in hypertensives with dyspnea. Hypertens Res. 2019; 42(2): 211-222, doi: 10.1038/s41440-018-0145-y, indexed in Pubmed: 30504821.

14. Woltjer HH, Bogaard HJ, Vries Pde. The technique of impedance cardiography. Eur Heart J. 1997; 18(9): 1396-1403, doi: 10.1093/ oxfordjournals.eurheartj.a015464.

15. Silver MA, Cianci P, Brennan S, et al. Evaluation of impedance cardiography as an alternative to pulmonary artery catheterization in critically ill patients. Congest Heart Fail. 2004; 10(2 Suppl 2): 17-21, indexed in Pubmed: 15073481.
16. Sadauskas S, Naudžiūnas A, Unikauskas A, et al. Applicability of Impedance Cardiography During Heart Failure Flare-Ups. Med Sci Monit. 2016; 22: 3614-3622, doi: 10.12659/msm.897529, indexed in Pubmed: 27721369.

17. Castellanos LR, Bhalla V, Isakson S, et al. B-type natriuretic peptide and impedance cardiography testing at the time of routine echocardiography predict subsequent heart failure events. J Card Fail. 2005; 11(6): S123, doi: 10.1016/j.cardfail.2005.06.124.

18. Bhalla V, Isakson S, Bhalla MA, et al. Diagnostic ability of B-type natriuretic peptide and impedance cardiography: testing to identify left ventricular dysfunction in hypertensive patients. Am J Hypertens. 2005; 18(2 Pt 2): 73S-81S, doi: 10.1016/j.amjhyper.2004.11.044, indexed in Pubmed: 15752936.

19. Castellanos LR, Bhalla V, Isakson S, et al. B-type natriuretic peptide and impedance cardiography at the time of routine echocardiography predict subsequent heart failure events. J Card Fail. 2009; 15(1): 41-47, doi: 10.1016/j.cardfail.2008.09.003, indexed in Pubmed: 19181293.

20. Ablonskytė-Dūdonienė R, Bakšytė G, Ceponienė I, et al. Prognosis of in-hospital myocardial infarction course for diabetic and nondiabetic patients using a noninvasive evaluation of hemodynamics and heart rate variability. Medicina (Kaunas). 2013; 49(6): 262-272, indexed in Pubmed: 24248006.

21. Brazdzionyte J, Macas A. Impedance cardiography for aortic balloon counterpulsation impact assessment on patients hemodynamics during acute myocardial infarction. Medicina (Kaunas). 2006; 42(11): 904-913, indexed in Pubmed: 17172792.

22. Neri M, Riezzo I, Pascale N, et al. Ischemia/Reperfusion Injury following Acute Myocardial Infarction: A Critical Issue for Clinicians and Forensic Pathologists. Mediators Inflamm. 2017; 2017: 7018393, doi: 10.1155/2017/7018393, indexed in Pubmed: 28286377.

23. Chen SJ, Gong Z, Duan QL. Evaluation of heart function with impedance cardiography in acute myocardial infarction patients. Int J Clin Exp Med. 2014; 7(3): 719-727, indexed in Pubmed: 24753769.

24. Malfatto G, Blengino S, Perego GB, et al. Transthoracic impedance accurately estimates pulmonary wedge pressure in patients with decompensated chronic heart failure. Congest Heart Fail. 2012; 18(1): 25-31, doi: 10.1111/j.1751-7133.2011.00248.x, indexed in Pubmed: 22277174. 